\title{
Cost of Asthma in Dubai, United Arab Emirates (UAE)
}

Bassam H Mahboub, FatehRahman SMA Shendi*, Basil Kh Safarini, Mostafa H AbdulAziz, Gamal M Mustafa and Vijayshree Prakash

Department of Internal Medicine, Pulmonary Unit, Rashid Hospital - Dubai Health Authority, UAE

\begin{abstract}
Background and Objectives: Asthma is one of the chronic respiratory diseases affecting both genders and all ages across the globe. The treatment and control of asthma imposes significant economic burden on patients as well as the healthcare system. Patients also report absenteeism from school/work and poor quality of life. There are very few studies evaluating the cost of asthma in UAE. The objective of this study is to evaluate the cost of asthma in Dubai region of United Arab Emirates.
\end{abstract}

Material and Methods: Asthma prevalence and unit cost estimates were applied to the population of Dubai aged 5 years and above, based on the figures from the Dubai Statistic Center 2009 census. The asthma treatment profiles of the patients in Dubai as well as the days absent from school/work and quality of life data were obtained from the Asthma Insights and Reality for the Gulf and Near East (AIRGNE) study. The cost of drugs was procured from the purchase department of Dubai Health Authority (DHA) and cost of out-patient visits as well as hospital stay and emergency visits was also provided by the DHA.

The cost of asthma in this study is the direct cost of drugs, hospital stay and visits as out-patient and ER visits, along with supplementary costs in terms of days lost from work or school.

Results: The total direct cost of asthma in Dubai was about 88 million Dirhams (AED 87,917,202). The maximum contribution to this was from expenditure on out-patient visits (37\% - AED 32,217,143), followed by that on hospital stays $(23 \%$ - AED $23,587,008)$. The cost on medication and ER visits represented $20 \%$ and $16 \%$ of the direct cost respectively.

Absenteeism from school was reported by $50 \%$ of asthmatic children, asthmatics also reported an average loss of 4 days of work per year due to asthma.

Conclusion: There is a huge economic burden on the patients and healthcare services due to asthma. Taking into account the considerable expenditure on the out-patient visits, ER visits and hospital stay, efforts must be directed towards improved asthma control and patient education about their disease.

\section{Introduction}

Asthma is a chronic respiratory disease characterized by chest tightness, wheezing, cough and shortness of breath. Approximately 300 million people around the globe suffer from asthma. It affects all ages and both genders; the prevalence varying between $1-18 \%$ in different countries across the world [1] .There is also a changing prevalence in countries over the past few years, which may be attributed to the change in awareness and diagnostic practices for asthma [2].

In the Middle East as well, there is inter and intra-regional variability in asthma prevalence. In Saudi Arabia, the prevalence was reported to be $23.6 \%$ [3], in Qatar it was 19.8\% [4] while that in Oman the prevalence varied between $7.8 \%$ to $17.3 \%$ in different regions [5]. A study from the $\mathrm{Al}$ Ain region of UAE shows asthma prevalence of $13 \%$ using the ISAAC questionnaire [6], while another based on the ECRHS questionnaire shows a range of $8-10 \%$ across UAE [7]. Despite this diversity in prevalence worldwide, there is a trend towards increase in diagnosed asthma, so much so that the prevalence has almost doubled in Europe over the past decade.

Asthma affects the quality of life adversely and adds to the economic burden of the patients and healthcare system. The expenditure on asthma control medication is not the only cost. Hospital visits including outpatient consultations, inpatient stay for disease control and absenteeism from work or schoolimpose additional cost. The AIRGNE data reports sickness absenteeism due to asthma in 30\% adult and $52 \%$ of children suffering from asthma per year [8].

The direct annual cost of asthma in Europe was estimated to be Euro 7.9 billion [9], while that in USA was USD 37.2 billion [10]. Another study in USA found the total incremental cost of asthma, including the indirect cost was USD 56 billion in 2007 [11].
The studies evaluating the cost of asthma from Middle East are very few, there are none from UAE. This study is thus aimed to estimate the expenditure for asthma treatment in Dubai. This includes the cost of asthma medication, out-patient visits, in-patient treatment and emergency visits. This can provide an insight for better management of asthma.

\section{Material and Methods}

The population of Dubai for age above 5 years was obtained based on the figures from the Dubai Statistic Center 2009 census. The data for drug use and cost of drug use was provided by the Dubai Health Authority (DHA) Purchasing Department. The treatment profiles were taken from the AIRGNE study [8]. The prevalence of asthma in Dubai was estimated using the Modified Delphi technique. This technique was used to gather consensus estimates of this data due to a lack of availability of unit costs of asthma treatment. One of the main advantages of using the Delphi technique is its ability to obtain expert knowledge from each participant without influence from other participants as opposed to a face-to-face group panel approach [12].

${ }^{*}$ Corresponding author: FatehRahman SMA Shendi, Department of Internal Medicine, Pulmonary Unit, Rashid Hospital - Dubai Health Authority, UAE; E-mail: fatehrahman@hotmail.com

Received December 27, 2012; Accepted April 19, 2013; Published April 22, 2013

Citation: Mahboub BH, SMA Shendi FR, Safarini BK, AbdulAziz MH, Mustafa GM et al. (2013) Cost of Asthma in Dubai, United Arab Emirates (UAE). J Pulmon Resp Med 3: 146. doi:10.4172/2161-105X.1000146

Copyright: (c) 2013 Mahboub BH, et al. This is an open-access article distributed under the terms of the Creative Commons Attribution License, which permits unrestricted use, distribution, and reproduction in any medium, provided the original author and source are credited. 
The Delphi panel methodology consisted of consensus consultations with seven leading physicians in asthma treatment in the UAE. Data was collected in two rounds from the panel were conducted to determine these estimates. In round 1, a summary of the best currently available data on asthma prevalence and unit costs of asthma treatment were provided to each of the panel members. Treatment costs included outpatient, Emergency Room (ER) visit, and inpatient costs for both adults and children. Each panel member provided their own expert estimates individually, including upper and lower estimates in addition to a "best" estimate. An average of the round 1 combined estimate from the panel members was calculated for each data input, and then used in round 2.

During round 2, the panelists were given these mean values to consider, and were given the opportunity to amend their round 1 estimates where they thought is appropriate to do so. These revised estimates for prevalence and costs (for both adults and children) generated in this second round were used in the main calculations of the current study.

For the arriving at the estimated prevalence, the panel members were asked to give three estimates of prevalence for both adults and children. The three estimates were for the lowest level of asthma prevalence (unlikely to be lower than this), the upper level of asthma prevalence (unlikely to be higher than this) and the best estimate (most likely).

\section{Cost Analysis}

The asthma prevalence determined in round 2 of the Delphi exercise was applied to the population of Dubai aged 5 and above. The product of percentage of patients being treated for asthma as reported in the AIRGNE study and the estimates from round 2 was then obtained to determine the total number of asthma patients managed in healthcare facilities.

The total outpatient cost was determined by multiplying the total number of asthma patients treated and the average number of annual out-patient visits as per the AIRGNE study [8].

Similarly, the ER visit and the total in-patient treatment expenditure was calculated by first multiplying the percentage of asthma suffers visiting ER as reported by the AIRGNE study by the total number of asthma patients being treated, then multiplying the product by the average number of ER visits per year in the AIRGNE study. The total number of annual ER visits thus obtained was then used to calculate the total cost of ER visits using the estimate obtained from the Delphi round 2 estimate of unit cost of ER visit. The total expenditure on the in-patient stay was calculated in a similar fashion.

To estimate the total direct treatment cost, it was assumed that the total direct cost of asthma was the sum of the out-patient costs, inpatient costs, cost of ER visits and the asthma medication cost.

A sensitivity analysis to the results from the Delphi panel was done based on the lowest $50 \%$ of values collected in round 1 Delphi.

The supplementary cost was assumed to be due to loss of work/ school-days due to asthma and poor quality of life. Data from the AIRGNE II was used for these assessments.

\section{Results}

The estimated asthma prevalence for the resident population of Dubai as estimated by the Delphi technique was $13.6 \%$ in adults and $19.2 \%$ in children (Table 1 ).
The estimated adult expenditure was AED 722 as the unit cost of hospitalization, while for a child it was AED 652 (Table 2).

According to the AIRGNE II data, 22\% of Dubai residents regularly use DHA facilities as their primary source of asthma management (Table 3).

The Out-patient visits accounted for the highest expenditure in the total direct cost for asthma, costing AED 22945342 for adults and AED 9271801 for children, the total expenditure being AED 32217 143 (Table 4).

This was followed by the cost of hospital stay due to asthma amounted to AED 23587 008, that for adults being AED 20412442 and for children being AED 3174566 (Table 5). Huge amount was also spent on emergency visits, a total of AED 17543 414, 44\% of adult and $38 \%$ of children with asthma visiting the ER in the past one year. Total number of ER visits per year for adults was 18,878 while that for children it was 3747 (Table 6)

The estimated total direct expenditure due to asthma in DHA facilities was AED 87,917,202, of which medication cost was AED 14 569637 (Table 7). The proportions of the total direct cost of asthma are shown in Graph 1.

\section{Supplementary Cost}

The indirect cost of asthma due to loss of days of work/school and poor quality of life is difficult to calculate in terms of revenue. The number of days of work lost due to asthma may reflect in loss of wages, thereby leading to monetary loss.

Based on the AIRGNE II data, 19\% of asthmatics in Dubai reported

\begin{tabular}{|l|l|l|l|l|l|l|l|}
\hline \multirow{2}{*}{$\begin{array}{l}\text { Delphi } \\
\text { and 2 }\end{array}$} & round 1 & \multicolumn{9}{|l|}{ Asthma Prevalence \% } \\
\cline { 2 - 8 } & Upper estimate & \multicolumn{2}{ll}{ Best estimate mean } & Lower estimate \\
\hline & Adult & Child & Adult & Child & Adult & Child \\
\hline Round 1 estimate & $40 \%$ & $50 \%$ & $14 \%$ & $21 \%$ & $6 \%$ & $11 \%$ \\
\hline Round 2 revised & & & $13.6 \%$ & $19.2 \%$ & & \\
\hline
\end{tabular}

Table 1: Estimated Asthma prevalence for Dubai.

\begin{tabular}{|l|c|c|c|c|}
\hline \multirow{2}{*}{$\begin{array}{c}\text { Mean cost in } \\
\text { Dubai }\end{array}$} & \multicolumn{4}{|c|}{ Cost visit or per day in DH } \\
\cline { 2 - 5 } & Outpatient & Emergency visit & Inpatient adult & Inpatient child \\
\hline Round 1 average & 225 & 565 & 633 & 560 \\
\hline Round 2 revised & 261 & 547 & 722 & 652 \\
\hline
\end{tabular}

Table 2: Cost per hospital visit in Government healthcare facilities in Dubai.

\begin{tabular}{|l|c|c|}
\hline Dubai & Adult 15+ & Children 5+ \\
\hline Population 2009 & $1,563,139$ & 136,816 \\
\hline Asthma prevalence & $13.6 \%$ & $19.2 \%$ \\
\hline Sub-total number of asthma sufferers & 212,587 & 26,228 \\
\hline \% regularly using DHA facilities (AIRGENE II) & $20.0 \%$ & $38.1 \%$ \\
\hline Total number of asthma sufferers using DHA & 42,517 & 9,993 \\
\hline
\end{tabular}

Table 3: Estimated asthma sufferers using DHA facilities.

\begin{tabular}{|l|c|c|}
\hline Dubai & Adults 15+ & Children 5+ \\
\hline Asthma sufferers using DHA facilities & 42,517 & 9,993 \\
\hline \% sufferers hospitalised in past year & $28 \%$ & $38 \%$ \\
\hline Total number of sufferers hospitalised & 11,777 & 3,747 \\
\hline Number of nights per patient in 12m & 2.4 & 1.3 \\
\hline Total number of nights hospitalized.a. & 28,266 & 4,871 \\
\hline Unit cost of an inpatient day/night DH & 722 & 652 \\
\hline Total cost of inpatient stays with DHA & $20,412,442$ & $3,174,566$ \\
\hline
\end{tabular}

Table 4: Estimated total cost of in-patient treatment for asthma in Dubai - DHA facilities. 
their asthma related limitation in activity affected their participation in sports and recreational activities a lot, while $44 \%$ reported some effect on sports and recreational activities. Physical exertion was somewhat limited for $40 \%$ while for $23 \%$, there was some correlation between their limitation in physical activity and choice of career. The extend of limitation of such activities that is due-to asthma is shown in Graph 2.

\section{Absenteeism from Work/School}

Leave from work / school was reported by $21 \%$ of asthmatics in

\begin{tabular}{|l|c|c|}
\hline Dubai & Adults 15+ & Children 5+ \\
\hline Total asthma sufferers using DHA facilities & 42,517 & 9,993 \\
\hline \% needing outpatient treatment in a year & $67 \%$ & $75 \%$ \\
\hline Total sufferers using DHA outpatient dept & 28,359 & 7,495 \\
\hline Outpatient visit per patient per year & 3.1 & 4.7 \\
\hline Total number of outpatient visits per year & 87,913 & 35,524 \\
\hline Unit cost of an outpatient visit DH & 261 & 261 \\
\hline Total cost of outpatient visits (DHA) DH & $22,945,342$ & $9,271,801$ \\
\hline
\end{tabular}

Table 5: Estimated total cost of out-patient visits for asthma in Dubai - DHA facilities.

\begin{tabular}{|l|c|c|}
\hline Dubai & Adults 15+ & Children 5+ \\
\hline Total asthma sufferers using DHA & 42,517 & 9,993 \\
\hline \% making emergency visit in past year & $44 \%$ & $38 \%$ \\
\hline Total number of ER visits & 18,878 & 3,747 \\
\hline Average number of visits per patient per year & 1.5 & 1.0 \\
\hline Total number of visits per year & 28,317 & 3,747 \\
\hline Unit cost of an emergency visit DH & 547 & 547 \\
\hline Total cost of emergency visits to DHA & $15,493,131$ & $2,050,283$ \\
\hline
\end{tabular}

Table 6: Estimated total cost of Emergency Visits for asthma in Dubai - DHA facilities.

\begin{tabular}{|l|c|c|c|}
\hline $\begin{array}{l}\text { 'Core' treatment cost in DHA } \\
\text { facilities }\end{array}$ & Adults 15+ & Child $\mathbf{5}$ to 14 & Totals \\
\hline Cost of outpatient visits & $22,945,342$ & $9,271,801$ & $32,217,143$ \\
\hline Cost of emergency visits & $15,493,131$ & $2,050,283$ & $17,543,414$ \\
\hline Cost of inpatient stays & $20,412,442$ & $3,174,566$ & $23,587,008$ \\
\hline Total non drug cost & $58,850,915$ & $14,496,650$ & $73,347,565$ \\
\hline Cost of medicines (DHA 2009) DH & & & $14,569,637$ \\
\hline Total direct cost of treatment (DH) & & & $87,917,202$ \\
\hline
\end{tabular}

Table 7: Estimated total direct cost for asthma in Dubai - DHA facilities.

\begin{tabular}{|c|c|c|c|c|}
\hline AIRGNE I : DUBAI (N= 68) & $\begin{array}{c}\text { TOTAL } \\
\text { DUBAI }\end{array}$ & $\begin{array}{c}\text { ADULT } \\
\text { DUBAI }\end{array}$ & $\begin{array}{c}\text { CHILD } \\
\text { DUBAI }\end{array}$ & $\begin{array}{c}\text { Controlled } \\
\text { ACT>20 }\end{array}$ \\
\hline missed day at work or school & $21 \%$ & $14 \%$ & $50 \%$ & $14 \%$ \\
\hline Figures for Europe (AIRE) & & $17 \%$ & $43 \%$ & \\
\hline
\end{tabular}

Table 8: Work-days lost due to asthma: calculation in working male population of Dubai.

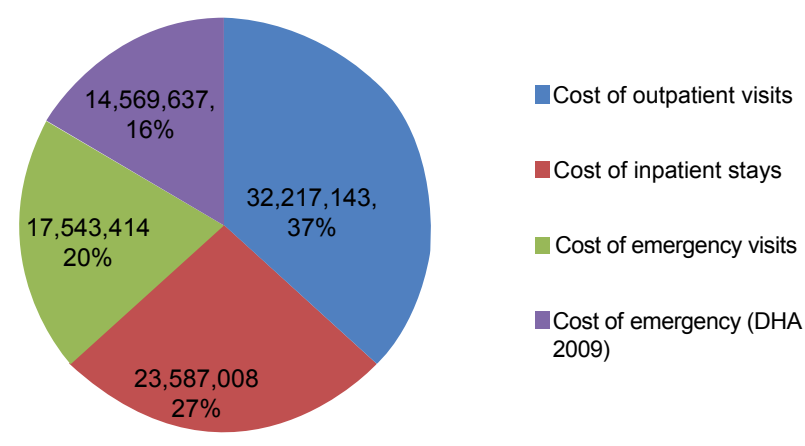

Graph 1: Percentage of total direct cost of asthma treatment.

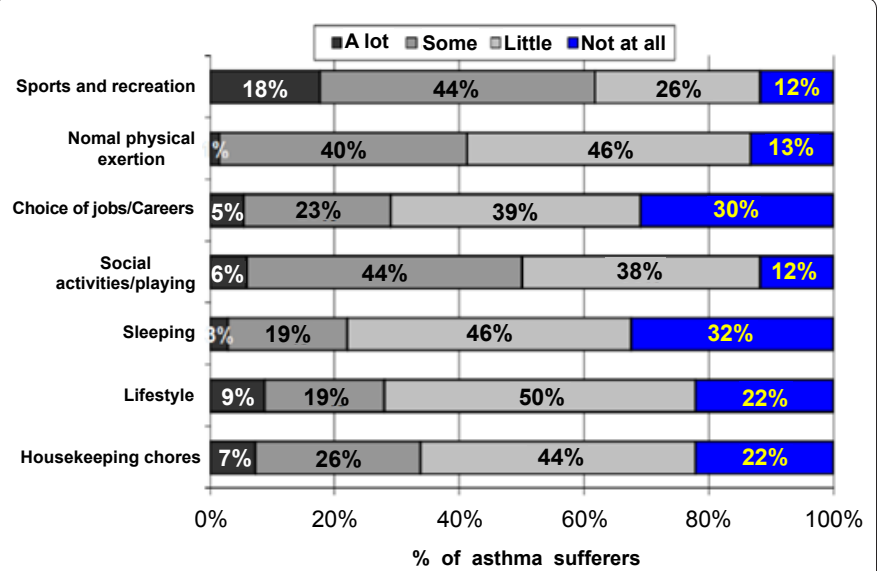

Graph 2: Extent of limitation of activities due to asthma (AIRGNE II).

Dubai according to the AIRGNE II study. Sickness absenteeism due to asthma was reported by $14 \%$ adults and $50 \%$ of school going children suffering from asthma. The average loss of days due to asthma was 4 per year.

Applying the estimated prevalence of asthma of $13.6 \%$ obtained by the Delphi technique to the population of working males (age 20-65 years) in Dubai according to the 2009 census, there is a loss of about 79000 work-days annually due to asthma.

\section{Discussion}

The high cost of asthma in Dubai is an economic burden on the healthcare system. The estimated total direct cost of treatment for asthma was AED 87, 917, 202 (approximately 88 million Dirhams). The highest cost was related to the out-patient visits representing $37 \%$ of the total cost (AED 32,217,143), followed by expenditure on hospital stay due to asthma (23\%) and ER visits (20\%). This expenditure (AED $73,347,565)$ was much higher than that on asthma medication (AED $14,569,637)$ which made up to $16 \%$ of the total direct cost.

The high financial burden is attributable to poor asthma control as evident by the high percentage of ER visits by asthmatics in the year preceding the study. This percent $(44 \%)$ is substantially high than in Europe, where only $10 \%$ of asthma sufferers needed to visit the ER. In addition, only $6 \%$ needed overnight hospitalization in Europe while in Dubai the percent was much higher $(28 \%$ in adults and $38 \%$ in children) [8,13].

In Europe, the cost for out-patient care was $48 \%$, drug cost was $46 \%$ and in-patient care cost was $6 \%$ [9], the largest portion of the total direct cost of asthma in US was expenditure on prescription medication and physician office visits - about $38 \%$ of the total incremental expenditure for asthma in children and $49 \%$ in adults [10].

The data from Dubai for sickness absenteeism due to asthma is close to that reported from Europe (14\% adults and 50\% children in Dubai \& $17.1 \%$ adults and $42.7 \%$ children in Europe).This may result into loss of wages, thus an indirect cost due to asthma.

In the sensitivity analysis, the 'best estimate' mean values from the Delphi exercise were replaced with mean values taken only from the 'lower estimate'. That meant we used asthma prevalence figures of $9 \%$ for adults and $15 \%$ for children. Although the effect of this change was to decrease the figure for the overall cost of asthma, the conclusions remained the same: that the main cost elements relating to asthma treatment in the DHA are those of emergency treatment, in patient 
treatment, and unscheduled outpatient treatment. These cost elements reflect poorly controlled asthma and it follows that the prime focus should be on improving control of asthma and not on reducing drug costs.

There are certain drawbacks of this study. These figures are estimates in cost and prevalence based on individual judgment although the reliability of the estimates is increased due to use of two rounds of estimates and sensitivity analysis.

Furthermore, the population in Dubai is a heterogeneous group of local Arab and expatriate people. The figures in this study are thus the best that could be represented.

\section{Conclusion}

Expenditure due to asthma is a substantial burden on the healthcare system. The cost of asthma for hospital stay, out-patient visits and Emergency visits is considerably higher than that of the medication cost. The efforts should hence be directed towards achieving better asthma control by means of patient education and disease awareness.

\section{References}

1. Masoli M, Fabian D, Holt S, Beasley R; Global Initiative for Asthma (GINA) Program (2004) The global burden of asthma: executive summary of the GINA Dissemination Committee report. Allergy 59: 469-478.

2. Pearce N, Aït-Khaled N, Beasley R, Mallol J, Keil U, et al. (2007) Worldwide trends in the prevalence of asthma symptoms: phase III of the International Study of Asthma and Allergies in Childhood (ISAAC). Thorax 62: 758-766.

3. Nahhas M, Bhopal R, Anandan C, Elton R, Sheikh A (2012) Prevalence of allergic disorders among primary school-aged children in Madinah, Saudi Arabia: two-stage cross-sectional survey. PLoS One 7: e36848.

4. Janahi IA, Bener A, Bush A (2006) Prevalence of asthma among Qatari schoolchildren: International Study of Asthma and Allergies in Childhood, Qatar. Pediatr Pulmonol 41: 80-86.

5. Al-Rawas OA, Al-Riyami BM, Al-Kindy H, Al-Maniri AA, Al-Riyami AA (2008) Regional Variation in the Prevalence of Asthma Symptoms among Oman School Children: Comparisons from Two Nationwide Cross-sectional Surveys Six Years Apart. Sultan Qaboos Univ Med J 8: 157-164.

6. Al-Rawas OA, Al-Riyami BM, Al-Kindy H, Al-Maniri AA, Al-Riyami AA (2008) Regional Variation in the Prevalence of Asthma Symptoms among Oman School Children: Comparisons from Two Nationwide Cross-sectional Surveys Six Years Apart. Sultan Qaboos Univ Med J 8: 157-164.

7. Alsowaidi S, Abdulle A, Bernsen R (2010) Prevalence and risk factors of asthma among adolescents and their parents in Al-Ain (United Arab Emirates). Respiration 79: 105-111.

8. Mahboub $\mathrm{BH}$, Al-Hammadi $\mathrm{S}$, Rafique $\mathrm{M}$, Sulaiman $\mathrm{N}$, Pawankar R, et al. (2012) Population prevalence of asthma and its determinants based on European Community Respiratory Health Survey in the United Arab Emirates. BMC Pulm Med 12: 4.

9. Khadadah M, Mahboub B, Al-Busaidi NH, Sliman N, Soriano JB, et al. (2009) Asthma insights and reality in the Gulf and the near East. Int J Tuberc Lung Dis 13: $1015-1022$.

10. Loddenkemper R, Gibson GI, Sibille Y (2003) European Respiratory Society/European Lung Foundation. European Lung White Book. The first comprehensive survey on respiratory health in Europe. ERSJ.

11. Kamble S, Bharmal M (2009) Incremental direct expenditure of treating asthma in the United States. J Asthma 46: 73-80.

12. Barnett SB, Nurmagambetov TA (2011) Costs of asthma in the United States: 2002-2007. J Allergy Clin Immunol 127: 145-152.

13. Rosengart MR, Nathens AB, Schiff MA (2007) The identification of criteria to evaluate prehospital trauma care using the Delphi technique. J Trauma 62: 708-713.

14. Rabe KF, Vermeire PA, Soriano JB, Maier WC (2000) Clinical management of asthma in 1999: the Asthma Insights and Reality in Europe (AIRE) study. Eur Respir J 16: 802-807. 